\title{
ANÁLISE DO CAMPO DE FORÇAS EM RELAÇÃO A IMPLANTAÇÃO DO PROGRAMA DE GESTÃO DA QUALIDADE EM UMA MATERNIDADE ESCOLA - RELATO DE EXPERIÊNCIA
}

Autores: Roberta de F. da N. Souza[1]; Raphael B. de A. Santos [1]; Nilma D. L. Costão [2] ; Vilani M. A.Nunes ${ }^{[2]}$.

QualiSaúde ${ }^{\circledR}$

\section{INTRODUÇÃO}

O conceito de qualidade engloba várias dimensões, dentre elas: equidade, efetividade, eficiência, acessibilidade e segurança, envolvendo diversos fatores da assistência, sendo importante sua análise e discussão contínuas nos serviços de saúde. Como estratégia de implantação da gestão da qualidade nos serviços de saúde, destaca-se a análise do campo de forças, através da averiguação das forças contrárias, que dificultam as mudanças a serem implantadas, e das forças favoráveis a melhoria desejada. Com isso, são traçadas estratégias focadas no reforço das forças favoráveis e diminuição das forças contrárias.

\section{OBJETIVO}

Relatar a realização de uma análise do campo de forças em uma Maternidade Escola, em relação a implantação do Programa de Gestão da Qualidade(PGC).

\section{METODOLOGIA}

Trata-se de um estudo do tipo relato de experiência, vivenciado pelos autores do estudo no Curso de Pós-Graduação em Gestão da Qualidade dos Serviços de Saúde, da Universidade Federal do Rio Grande do Norte, como atividade prática do Módulo I- Planejamento e Implantação de Programas de Gestão de Qualidade em Serviços de Saúde, do curso supracitado.

\section{RESULTADOS}

FORÇAS A

FAVOR
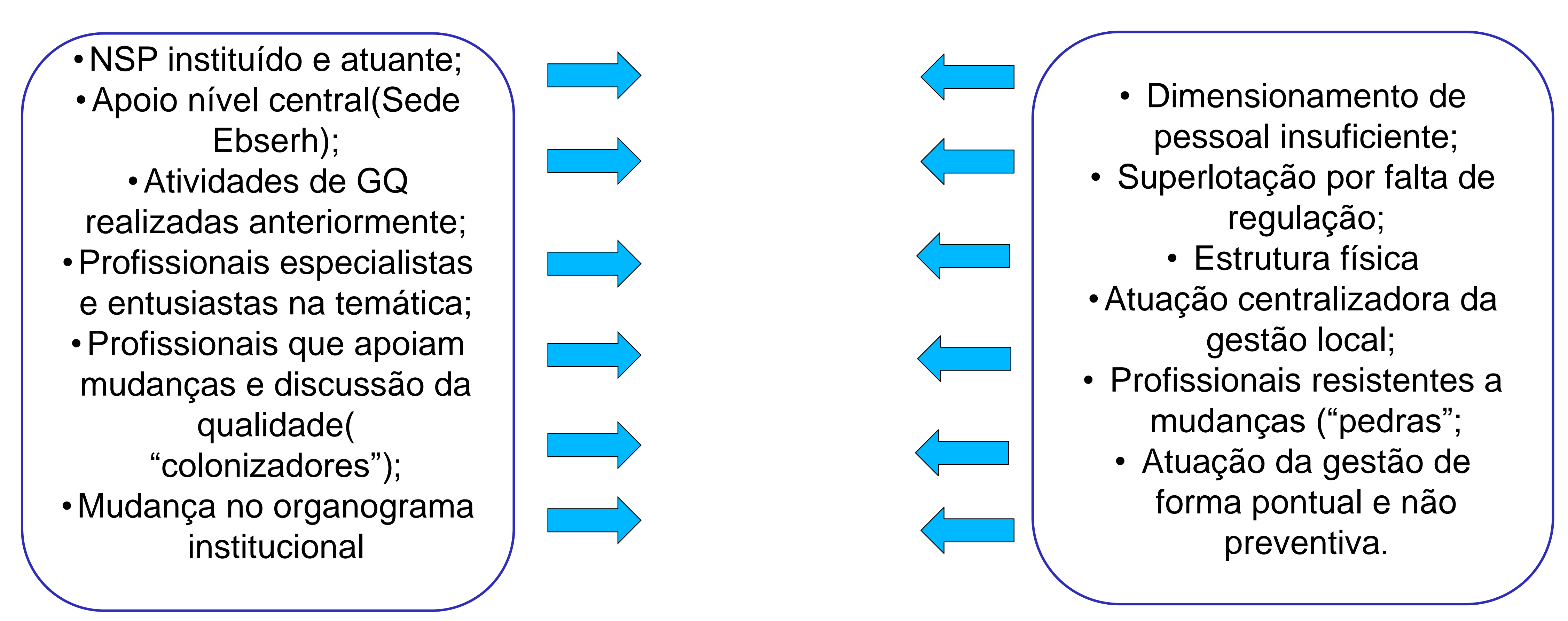

FORÇAS

CONTRÁRIAS

\section{CONCLUSÃO}

Com a realização do instrumento observou-se que as forças facilitadoras e contrárias estão equilibradas, podendo afirmar que a MEJC possui campo favorável para aplicação de estratégias que viabilizem a implantação do PGQ.

\section{REFERÊNCIAS:}

1. GAMA, Z. ; SATURNO, P. A segurança do paciente inserida na gestão da qualidade dos serviços de saúde. Agência Nacional de Vigilância Sanitária, editor. Assistênica segura: uma reflexão teórica aplicada à prática, p.29-40,2013.

2. LEWIN, K. Deflining the "Field at a given time". Psychological Review, v.50, p.292-310, 1943. In: Resolving Social Conflicts Field Theory in Science. American Psychological association, 1997. 